\title{
Sperm morphology and DNA fragmentation after zona pellucida selection
}

\author{
Rumiana GanevaD1, Dimitar Parvanov1, Denitsa Velikova2, Magdalena Vasileva3 ${ }^{3}$ Kristina Nikolova $^{3}$ and \\ Georgi Stamenov 4
}

${ }^{1}$ Research Department, Nadezhda Women's Health Hospital, Sofia, Bulgaria ${ }^{2}$ Andrology Department, Nadezhda Women's Health Hospital, Sofia, Bulgaria 3Embryology Department, Nadezhda Women's Health Hospital, Sofia, Bulgaria ${ }^{4}$ Obsterics and Gynecology Department, Nadezhda Women's Health Hospital, Sofia, Bulgaria

Correspondence should be addressed to R Ganeva: rum.ganeva@gmail.com

\begin{abstract}
Sperm DNA fragmentation (SDF) and sperm morphological defects can negatively affect ART outcomes. Consequently, there is a need for additional semen processing technique that accounts for sperm DNA status and morphology prior to ICSI. The objective was to evaluate the efficacy of an additional zona pellucida adhesion-based sperm selection for obtaining sperm populations with a high percentage of normal morphology and DNA integrity as compared to native semen and routine swim-up preparation. Semen samples from 78 normozoospermic men were subjected to swim up and placed in petri dishes coated with 48 acid-solubilized zonae pellucidae. Sperm DNA fragmentation and morphology were assessed in the native semen, the swim-up samples, and the zona-adhered spermatozoa from each patient. The mean sperm DNA fragmentation of the zona-selected spermatozoa $(3.5 \pm 0.7 \%)$ was significantly lower than the swim-up samples $(15.3 \pm 5.2 \%)(P<0.001)$ and native semen $(24.9 \pm 7.1 \%)(P<0.001)$. All of the samples had lower levels of DNA damage after additional selection by zona pellucida adhesion. Significantly higher percentage of sperm with normal morphology was observed after zona-adhesion selection $(11.4 \pm 3.9 \%)$ when compared to the swim-up samples $(8.9 \pm 4.3 \%)(P<0.001)$ or the native semen $(5.3 \pm 3.2 \%)(P<0.001)$. In $94 \%$ of the samples, the percentage of spermatozoa with normal morphology increased after the additional zona selection. This study demonstrates that sperm selection by additional zona-adhesion technique yields a significantly higher percentage of spermatozoa with normal morphology as well as a significantly decreased level of DNA fragmentation when compared to the native semen and the swim-up-only prepared samples.
\end{abstract}

\section{Lay summary}

High level of DNA folding known as sperm DNA fragmentation (SDF) inside each sperm and defects in the shape, size, and structure of the sperm can negatively affect assisted reproduction treatment (ART) outcomes. Consequently, there is a need for additional semen processing techniques that account for sperm quality prior to ART. Our team designed a simple technique using proteins from the coat around the egg (zona pellucida) to enhance sperm selection procedures based on natural sperm-egg interactions. Using this technique in combination with the most common techniques used in ART yields a significantly higher percentage of sperm with normal shape, size, and structure and a decreased level of DNA fragmentation. This sperm zona-selection technique would be beneficial if introduced in the ART practice to yield sperm with higher fertilization potential.

Key Words: - sperm DNA fragmentation (SDF) \ zona adhesion \ zona pellucida $\quad$ sperm selection $\quad$ sperm morphology Reproduction and Fertility (2021) $221-230$

https://raf.bioscientifica.com

https://doi.org/10.1530/RAF-21-0041 (c) 2021 The authors Published by Bioscientifica Ltd

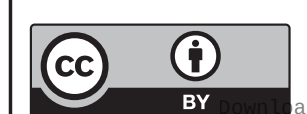

This work is licensed under a Creative Commons Attribution 4.0 International License. 


\section{Introduction}

About $30 \%$ of infertile couples are diagnosed with idiopathic infertility due to lack of any evident pathology (Sadeghi 2015). In many such cases, though, ART failures can be attributed to the so-called 'hidden' male factor (Mackenna 1995). Currently, routine semen analysis, based on the evaluation of sperm count, sperm mobility, and morphology alone, provides valuable but superficial information about male fertility status. Despite being classified as normozoospermic, some men are still infertile (Wang \& Swerdloff 2014).

The main characteristic used for determining the quality of the individual spermatozoa is their morphology (Gatimel et al. 2017). Morphological abnormalities of the sperm head havelong been associated with low fertilization, implantation, and pregnancy rates (Kruger et al. 1988, Kahraman et al. 1999, Osawa et al. 1999). Therefore embryologists tend to select morphologically normal spermatozoa for ICSI. Recently other sperm characteristics have emerged as important markers of sperm quality, such as sperm DNA fragmentation (SDF) (Jin et al. 2015, Chen et al. 2020) and the sperm zona-adhesion ability (Hamada et al. 2012, Ganeva et al. 2019a).

Numerous studies have investigated the significance of sperm DNA integrity in male infertility (Cissen et al. 2016). It has been shown that SDF has an even higher predictive value for male fertility and reproductive outcomes than routine semen analysis (Kodama et al. 1997, Evenson et al. 1999, Zini et al. 2001). Some authors go as far as to claim that sperm DNA damage can have a detrimental effect on fertilization (Hamada et al. 2012), preimplantation embryonic development (Chi etal. 2017), and implantation (Jin et al. 2015). Moreover, high DNA fragmentation in spermatozoa used for ICSI has been related to increased incidence of miscarriage (Gil-Villa et al. 2010) and high rates of morbidity in the offspring (Fernandez-Gonzalez et al. 2008).

It is still debatable whether the conventional sperm preparationbyswim-upanddensity-gradientcentrifugation reduces the percentage of DNA fragmentation (Wang et al. 2014) or, on the contrary, causes the generation of reactive oxygen species impairing sperm DNA integrity (Quinn et al. 2018). Meanwhile, several techniques have been proposed for obtaining motile spermatozoa without DNA fragmentation such as modified hyaluronan binding (Parmegiani et al. 2014), microfluidic sperm sorting devices (Quinn et al. 2018, Parrella et al. 2019), and motile sperm organelle morphology examination (Bartoov et al. 2003, Garolla et al. 2014).
However, following the natural sperm selection process, another non-invasive approach has emerged (Ganeva et al. 2019b). The sperm-zona binding plays a crucial role in natural fertilization and is one of the major selective stages during the spermatozoa transition through the female tract (Liu \& Baker 2000).

The ability of sperm to adhere to zona pellucida has been shown to relate to their fertilization potential and eventual IVF success (Liu et al. 1989, Ganeva et al. 2019a, 2019c). Liu and Baker (2007) showed that defective sperm-zona pellucida interaction is a significant cause of fertilization failure. The lack of zona-adhesion ability of the spermatozoa indicates lower chances of success after IVF or IUI (Liu \& Baker 2000, Arslan et al. 2006).

It has been shown that the ability of sperm to bind to the zona correlates with the DNA fragmentation of the native semen (Liu \& Baker 2007). Moreover, it has been suggested that zona-binding ability can be negatively affected by SDF (Kumar et al. 2013). In 2007, Liu and Baker used the hemizona technique to demonstrate that zona pellucida is highly selective for spermatozoa bearing dsDNA (Liu \& Baker 2007). The selectivity of the zona pellucida for spermatozoa with normal morphology had already been proven using native zonae (Liu \& Baker 1992, 1994), and the possibility of retrieving those spermatozoa for ICSI had already been discussed (Braga et al. 2009, Liu 2011). A number of studies have since confirmed that using zona-bound spermatozoa in ICSI improves fertilization and implantation rates and results in fewer miscarriages (Black et al. 2010, Liu 2011, Jin et al. 2016, Ganeva et al. 2019c). Compared to conventional ICSI, the use of zonaselected spermatozoa for ART has also been shown to result in improved embryo quality (Liu et al. 2011, Ganeva et al. 2019b).

Most of the sperm zona-selection techniques available today are still relatively complex and tedious to use in the IVF lab routine, and there is still a need for a simpler, more reliable, yet equally effective solution.

In the light of these statements, our team designed a simple technique using native zona pellucida proteins to possibly enhance sperm zona-adhesion test (Ganeva et al. 2019 c) and zona-adhesion-based selection procedures. The proposed technique employs a zona protein pool obtained by acid solubilization of zonae pellucidae from healthy donors, subsequently immobilized on flat petri dishes, making it simple to use and handle, and allowing easy observation and isolation of sperm.

This study aims to evaluate the DNA status and morphology of spermatozoa selected by an addition to the conventional swim-up preparation, zona pellucida adhesion 
selection method and to compare them with the same patient's native semen and swim-up-only prepared samples.

\section{Materials and methods}

\section{Patients}

This study includes semen samples from 78 normozoospermic male patients of a private hospital between February 2020 and March 2020 after approval of IRB (N 2/18.01.2020). Zonae pellucidae were obtained from 30 healthy donors' germinal vesicles (GVs) after regular follicular puncture for egg donation. All included subjects signed written informed consent.

\section{Experimental design}

In this study, sperm morphology evaluation and SDF were compared between native semen, swim-up-only prepared spermatozoa, and those subjected to double selection (swim-up and zona pellucida adhesion) in patients with normozoospermia. SDF test was conducted on frozen samples to minimize differences in the staining procedure.

Semen samples were collected by masturbation after 3-5 days of sexual abstinence. After semen liquefaction for $30 \mathrm{~min}$ at $37^{\circ} \mathrm{C}$, an aliquot was used for regular semen analysis in accordance with World Health Organization guideline (2010) including sperm morphological evaluation according to Kruger's strict criteria, while another aliquot of native semen was frozen in sperm freezing medium (Origio, Denmark) in liquid nitrogen at $-196^{\circ} \mathrm{C}$ for further analysis.

The remaining semen was washed in a sperm wash buffer (Origio, Denmark) by centrifugation at $600 \boldsymbol{g}$ for 5 min and subjected to a standard swim-up preparation (15 min in $37^{\circ} \mathrm{C}$ at 45 degrees angle) in Global for fertilization (Life Global, Belgium) supplemented with 1\% HSA v/v (Life Global, Belgium). One-half of the isolated motile spermatozoa (swim-up-only sample) were used for morphological evaluation and frozen in liquid nitrogen at $-196^{\circ} \mathrm{C}$ for further analysis. The other half was subjected to the sperm zona-adhesion selection as described below and the zona adhered spermatozoa were also subjected to Kruger's strict morphological evaluation and frozen in liquid nitrogen at $-196^{\circ} \mathrm{C}$ for further analysis.

\section{Sperm zona-adhesion selection}

Sperm zona-adhesion selection was performed as previously described (Ganeva et al. 2019c). Briefly, 48 zonae pellucidae from 30 healthy donors' germinal vesicles (GVs) were acid solubilized as each zona pellucida was placed in $5 \mu \mathrm{L}$ drops of $\mathrm{HCl} 20 \% \mathrm{v} / \mathrm{v}$ for $5 \mathrm{~min}$, and the solubilization was observed under light microscopy. The acid solubilized zona solutions were combined in zona pellucida protein pool, and the solution was neutralized with $\mathrm{NaOH}$ to $\mathrm{pH}$ 7.4. The protein concentration was measured by the Bradford quantification method (Bradford 1976). The zona pellucida protein pool was diluted in carbonate buffer (pH7.4) to the concentration of $50 \mu \mathrm{g} / \mathrm{mL}$ and $10 \mu \mathrm{L}$ drops of the zona solution were immobilized by air drying on petri dishes. The zona pellucida coated surfaces were then covered with $10 \times 10^{6}$ motile spermatozoa from each patient. After 30 min of incubation at RT, the petri dishes were washed from the unadhered spermatozoa. The adhered spermatozoa were detached by vigorous pipetting.

\section{Sperm DNA fragmentation (SDF) detection}

In this study, all samples have been frozen under the same protocol so as to be stained and analyzed at the same time to avoid differences in the preparation method and the quality of the reagents used. Determination of DNA damage was performed using the halosperm G2 kit (Halotech, Spain) on frozen samples according to the manufacturer's instructions. After thawing native semen, swim-up-only prepared spermatozoa and zona adhered spermatozoa concentrations were adjusted to $20 \times 10^{6} / \mathrm{mL}$. Each sample was done in duplicate and at least 300 spermatozoa on each slide were scored. Results were calculated as the percentage of sperm with fragmented DNA.

\section{Sperm morphology}

Native semen, swim-up-only prepared spermatozoa, and zona adhered spermatozoa concentrations were adjusted to $10 \times 10^{6} / \mathrm{mL}$. Sperm morphology was assessed according to Kruger's strict criteria. To minimize the counting error, each sample was done in duplicate and at least 300 spermatozoa on each slide were scored.

\section{Statistical analysis}

Statistical analysis was performed using IBM SPSS Statistics v.21 Software, and figures were prepared using Prism version 8 by Graph Pad Software. The normality of the variables was analyzed by the Kolmogorov-Smirnov test. Data were analyzed by the Greenhouse-Geisser test. Results are shown as mean value \pm S.D. and range. Using power analysis, it was calculated that at least 54 subjects were required to detect a

This work is licensed under a Creative Commons Attribution 4.0 International License. 
medium effect size ( 0.25 S.D.) between the three groups at a significance level of 0.05 with a power of 0.80 .

\section{Results}

\section{Baseline characteristics of the studied patients}

This study includes 78 males with semen characteristics in the normal range of reference values defined by WHO fifth edition (Table 1).

Swim-up preparation resulted in a mean sperm concentration of $177.4 \times 10^{6} / \mathrm{mL}$ (S.D. 129.0 , range: $67.3-$ $234.1 \times 10^{6} / \mathrm{mL}$ ) with a mean number of spermatozoa $88.5 \times 10^{6}$ (S.D. 64.5 , range: $38.3-123.7 \times 10^{6}$ ). After zona pellucida adhesion on average $5.0 \times 10^{6}$ (s.D. 1.2, range: $\left.1.2-4.7 \times 10^{6}\right)$, spermatozoa were obtained.

\section{Sperm DNA fragmentation (SDF)}

In order to evaluate the effect of zona pellucida sperm selection on the SDF, we have compared the SDF of native semen, swim-up-only prepared spermatozoa, and zona adhered spermatozoa. The mean SDF in the native semen samples was $24.9 \%$ (S.D. $7.1 \%$, range 6-56\%). Statistical analysis showed that swim-up preparation reduced the percentage of DNA fragmentation significantly to $15.3 \%$ (S.D. $5.2 \%$, range: $0-41 \% ; P<0.001$ ) (Fig. $1 \mathrm{~A}$ ).

Moreover the additional selection through the applied zona binding procedure resulted in a significant reduction of DNA fragmentation compared to swim-up preparation $(3.5 \pm 0.7 \%$ vs $15.3 \pm 5.2 \%, P<0.001$, respectively). We found that in $92.3 \%(72 / 78)$ of the studied patients, a decrease in DNA fragmentation was observed after swim-up, but $100 \%$ (78/78) of the samples had lower DNA damage levels after additional selection by zona pellucida adhesion (Figs $2 \mathrm{~A}$ and 3 ).

Table 1 Baseline characteristics of the studied patients.

\begin{tabular}{|c|c|c|c|}
\hline & Mean \pm s.D. & Range & $\begin{array}{l}\text { WHO lower } \\
\text { ref limits }\end{array}$ \\
\hline Age, years & $36 \pm 5.4$ & $28-51$ & \\
\hline Semen volume, $\mathrm{mL}$ & $3.4 \pm 1.34$ & $1.6-8.6$ & $\geq 1.5$ \\
\hline $\mathrm{pH}$ & $7.8 \pm 0.2$ & $7.4-8.5$ & $\geq 7.2$ \\
\hline $\begin{array}{l}\text { Sperm concentration, } \\
\times 106 / \mathrm{mL}\end{array}$ & $92.4 \pm 60.7$ & $16.3-346$ & $\geq 15$ \\
\hline $\begin{array}{l}\text { Progressively motile } \\
\text { spermatozoa, } \%\end{array}$ & $50.36 \pm 7.73$ & $38-71$ & $\geq 32$ \\
\hline Overall motility, $\%$ & $52.9 \pm 9.9$ & $42-71$ & $\geq 40$ \\
\hline $\begin{array}{l}\text { Immotile } \\
\text { spermatozoa, } \%\end{array}$ & $42.6 \pm 8.5$ & $31-52$ & $\leq 60$ \\
\hline $\begin{array}{l}\text { https://raf.bioscientifica.com } \\
\text { https://doi.org/10.1530/RAF-2 }\end{array}$ & 0041 & Published & $\begin{array}{l}2021 \text { The authors } \\
\text { Bioscientifica Ltc }\end{array}$ \\
\hline
\end{tabular}

\section{Sperm morphology}

To evaluate the efficacy of the combined swim-up and sperm zona-selection procedure, the morphology of the native semen, swim-up-only prepared spermatozoa, and zona adhered spermatozoa were compared. Morphologically normal spermatozoa in the native semen samples were $5.3 \pm 3.2 \%$. Swim-up preparation significantly increased the percentage of morphologically normal spermatozoa to $8.9 \pm 4.3 \%(P<0.001)$ (Fig. 1B).

The additional zona-adhesion selection technique significantly increased the mean percentage of sperm with normal morphology compared to the swim-up prepared samples $(11.4 \pm 3.9 \%$ vs $8.9 \pm 4.3 \%, P<0.001)$. Furthermore, in $94 \%$ (74/78) of the samples, the percentage of spermatozoa with normal morphology increased after the additional zona selection (Fig. 2B).

Furthermore, the three groups of morphological defects (head, midpiece, and head defects) in the native semen, swim-up-only prepared spermatozoa, and zona adhered spermatozoa were also compared. Swim-up significantly reduced the incidence of neck defects $(P<0.001)$ and tail defects $(P<0.001)$ in comparison to the native semen but not the percentage of head defects $(P=0.155)$. However head defects, unlike neck and tail defects, were significantly lower after combined swim-up and zona selection in comparison to the native semen $(P=0.037)$ and swim-up-only samples $(P=0.039)$ (Fig. 2C).
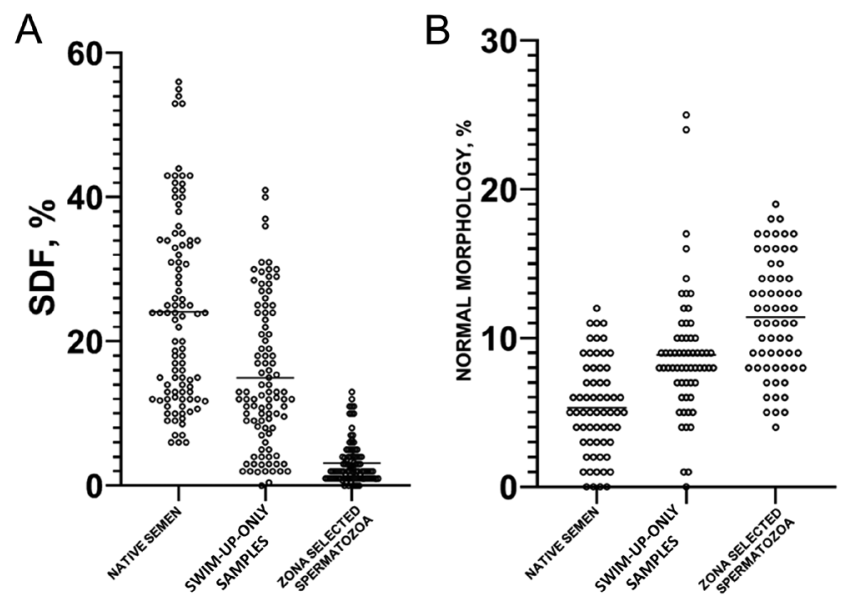

Figure 1 Column scatter plots of (A) sperm DNA fragmentation index (SDF) in native semen, swim-up-only samples, and zona-selected spermatozoa; (B) Percentage of morphologically normal spermatozoa in native semen, swim-up-only samples, and zona-selected spermatozoa. 

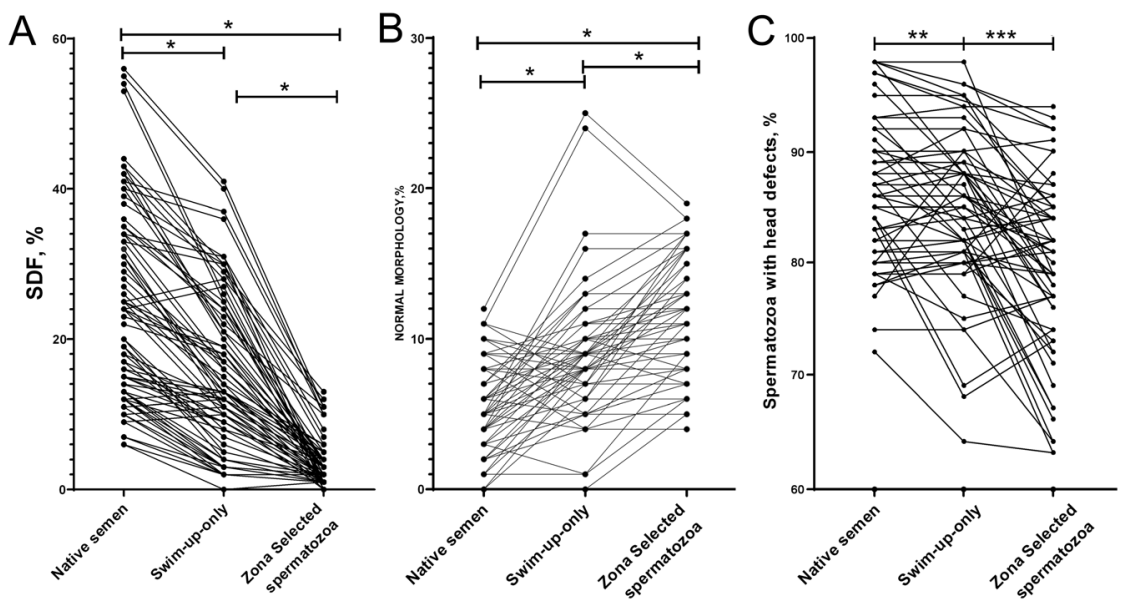

Figure 2 (A) Comparison of the proportion of sperm with damaged DNA in native semen, swim-up-only samples, and zona-selected spermatozoa. Each line represents an individual subject. There was a significant decrease in the SDF from native semen to swim-up-only samples ( $\left.{ }^{*} P<0.001\right)$ and from swim-up-only samples to zona-selected spermatozoa ( $* P<0.001$ ). (B) Comparison of the proportion of sperm with normal morphology in native semen, swim-up-only samples, and zona-selected spermatozoa. Each line represents an individual subject. There was a significant increase in the percentage of spermatozoa with normal morphology from native semen to swim-up-only samples ( ${ }^{*} P<0.001$ ) and from swim-up-only samples to zona-selected spermatozoa ( ${ }^{*} P<0.001$ ). (C) Comparison of the proportion of sperm with head defects in native semen, swim-up-only samples, and zona-selected spermatozoa. Each line represents an individual subject. There was a significant decrease in the percentage of head defects from native semen to zona-selected spermatozoa ( $* * P=0.037$ ) and from swim-up-only samples to zona-selected spermatozoa ( ${ }^{\star \star \star} P=0.039$ ).

\section{Discussion}

A high percentage of the infertile couples are still classified as having unexplained infertility due to lack of evident pathology and male partners having a normozoospermia (Sadeghi 2015). The routine semen analysis and the current methods of sperm selection are unable to detect some important sperm characteristics such as zonaadhesion ability or DNA damage (Mackenna 1995, Wang $\&$ Swerdloff 2014).

Defective sperm-zona pellucida adhesion is one of the main causes for low fertilization rates in IVF programs (Liu \& Baker 2000). Half of the patients experiencing repeated IVF failures with normal semen characteristics show disrupted sperm-zona interaction (Liu \& Baker 2003). Also, high percentages of infertile couples with normozoospermic partners have a high level of SDF (Saleh et al. 2002). These patients are directed to ICSI rather than IVF because it has been shown that it leads to higher pregnancy rates (Li et al. 2006, Zhao et al. 2014, Zhang et al. 2015). Therefore couples experiencing repeated IVF failures with normal semen parameters would benefit from ICSI with additional sperm preparation techniques that would select the spermatozoa with intact DNA and membrane maturity for best chances of fertilization.

The exact role of sperm DNA fragmentation, especially in ICSI cycles, is still not fully clear. While some authors comment that increased SDF does not significantly affect ART outcomes (Sharbatoghli et al. 2012, Dar et al. 2013), other studies link DNA damage to failed IVF attempts (Osman et al. 2015). Nevertheless, there seems to be a consensus about the negative effect of sperm DNA damage on embryo development (Zheng et al. 2018) and embryo implantation success (Parikh et al. 2019). Some metaanalyses reveal a general trend for a high impact of SDF on the incidence of miscarriages (Robinson et al. 2012, Tan et al. 2019). Therefore, optimizing the sperm preparation before IVF to minimize the DNA fragmentation effect would be definitely beneficial for ART outcomes.

Swim-up is a ubiquitously used technique for sperm preparation preceding ART due to its effectiveness in obtaining a motile sperm population with a low percentage

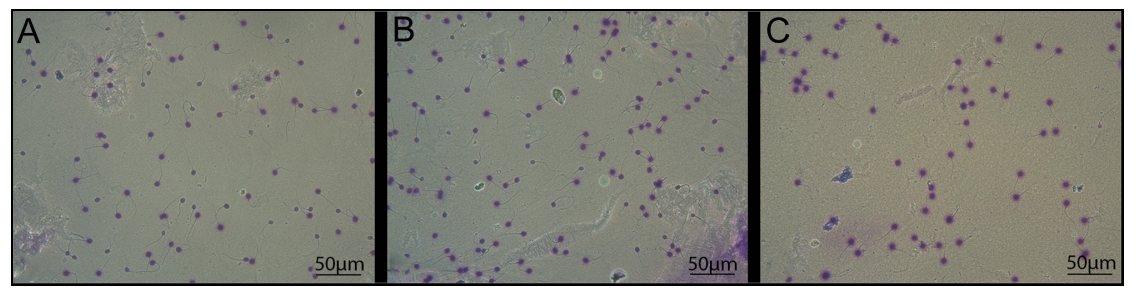

Figure 3 Visualization of the sperm DNA fragmentation in spermatozoa from the same subject under light-microscopy. (A) Sperm sample showing high SDF in native semen. (B) Sperm sample with lower SDF after swim-up-only. (C) Sperm sample showing the lowest SDF after the zona-selection procedure.

https://raf.bioscientifica.com https://doi.org/10.1530/RAF-21-0041 (c) 2021 The authors Published by Bioscientifica Ltd

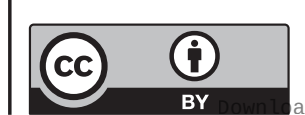

This work is licensed under a Creative Commons Attribution 4.0 International License. 
of apoptotic sperm (Ricci et al. 2009). However, previous studies have shown that routine sperm preparation and processing increase the levels of DNA fragmentation due to the excessive amounts of ROS produced during centrifugal pelleting (Jayaraman et al. 2012, Muratori et al. 2019). Consequently, there is a growing need for additional semen processing techniques that account for sperm DNA status prior to IVF (Stevanato et al. 2008, Jayaraman et al. 2012).

For this reason, we have implemented a modified and improved zona pellucida-based selection procedure. This study was designed to investigate how effectively this sperm processing technique could remove DNA-damaged and morphologically abnormal spermatozoa compared to the routinely used swim-up method.

In our study, spermatozoa were isolated based on their ability to adhere to zona pellucida proteins. This selection method has been debated for decades (Braga et al. 2009) and different approaches have been tried, such as hemizona assay (HZA) (Burkman et al. 1988, Menkveld et al. 1991) and the sperm-ZP binding ratio test in which intact oocytes are used (Liu et al. 1988). Authors applying this approach report a positive effect of zona pellucida selection on ART outcomes like fertilization rate, embryo quality, implantation rate, as well as decreased miscarriage rates (Braga et al. 2009, Jin et al. 2016). This effect was also confirmed by our previous study, which demonstrated an increase in embryo quality and higher implantation rates in couples with zona-selected sperm for ICSI (Ganeva et al. 2019b). A possible explanation for this tendency is the significantly more efficient selection of a spermatozoa population with normal morphology and lower DNA fragmentation through zona-adhesion, also observed in the present study.

The approach in this study applies a solubilized pool of homogenized zona pellucida proteins and providing a flat sperm adhesion surface. This differs from other sperm zona-binding techniques where whole or half zona with native structure is used as adhesion surface (Oehninger et al. 2013, Kizilay \& Altay 2017). Techniques using whole or half zonae suffer from a major drawback, limiting the consistency and reliability of results due to the fact that the sperm adhesion to the intact or half zonae is affected by the zona diameter (Burkman et al. 1988), surface appearance (Familiari et al. 1988), and the thickness of the zona matrix (Franken et al. 1991). This undesirable spermbinding variation between the individual zonae is avoided in the method used in this study by using a homogenized pool of dissolved zonae pellucidae from different women (Ganeva et al. 2019c). Future studies for implementing zona pellucida selection in the clinical practice would require applying homologous zonae. Using zonae pellucidae from the same patients, previous cycles could personalize the process of sperm preparation for the routine practice. Also, the method for ligand immobilization on a flat surface was proven to be an efficient technique in other sperm isolation procedures as it allows for easy observation of the adhered spermatozoa and their subsequent selection for IVF or ICSI (Huszar et al. 2003, Szucs et al. 2015).

Both sperm preparation methods employed in the present study (swim-up and zona pellucida selection) yielded sperm populations with significantly lower DNA damage than the native, unprocessed fraction. Sperm preparation through combined swim-up and zona adhesion resulted in a substantially increased percentage of spermatozoa with intact chromatin compared to the conventional swim-up, which could improve the chance of achieving a successful pregnancy and live birth after ART treatment. The positive effect of the combined swim-up and zona-selection procedure is due to the selection of motile spermatozoa (by swim-up) and andthe additional selection of functionally mature spermatozoa (by zona-adhesion selection). The immature spermatozoa bearing highly fragmented DNA and the morphologically abnormal spermatozoa are unable to pass these two stages of selection. These results are in agreement with previous studies that apply a similar procedure for zona pellucida sperm selection. In 2007, Liu and Baker concluded that zona pellucida is highly selective for spermatozoa bearing dsDNA. Other authors report not only minimal DNA fragmentation but also a lower frequency of chromosomal aneuploidies of both hyaluronan-bound and zona pellucida-bound spermatozoa (Yagci et al. 2010). In addition, our results demonstrate that spermatozoa that successfully adhered to the solubilized zona pellucida pool have better morphology. The selectivity of the zona pellucida for spermatozoa with normal morphology has been already demonstrated by other authors using native zonae (Liu \& Baker 1992, 1994). Therefore it can be suggested that zona pellucida is a sensing barrier for spermatozoa bearing both disrupted DNA and morphological modifications. The molecular mechanisms behind this selective stage of fertilization are still unclear. However, studies have shown an inherent relation between SDF and poor sperm morphology, particularly sperm head defects (Skowronek et al. 2012, Jakubik-Uljasz et al. 2020).

Furthermore, it has been shown that spermatozoa attachedtothezonapellucidapossessspecificmorphological characteristics, particularly in the acrosomal region (Liu \& Baker 1992, Garrett et al. 1997). Acrosomal abnormalities 
in otherwise morphologically normal sperm have been shown to correlate with an impaired zona-binding ability (Liu \& Baker 1992, Menkveld et al. 1996), and even sperm with round heads and missing acrosome do not bind to the zona pellucida at all (Von Bernhardi et al. 1990, Bourne et al. 1995). Also, zona pellucida seems to have specific sperm morphometric preferences (Garrett et al. 1997), which was further confirmed by the fact that a defect in the zona-binding protein gene (zpbp1) in men leads to sperm head morphological anomalies and no zona binding (Yatsenko et al. 2012). Mice lacking Zpbp1 have defective sperm head morphology with characteristics reminiscent of teratozoospermia in infertile men due to the increased number of head abnormalities (Lin etal. 2007). These results were confirmed in our study, which indicates that zona adhered spermatozoa have a significantly lower percentage of head abnormalities than the native semen and the swim-up-only samples. Even though numerous studies have confirmed the selectivity of human zona pellucida for sperm with normal morphology, some authors found that sperm with specific morphological abnormalities can still successfully bind to the zona (Liu et al. 1988, Garrett et al. 1997). In our study, it is also shown that the percentage of the overall midpiece and tail abnormalities did not differ significantly between the zona-selected spermatozoa and the native semen.

While it is true that ICSI itself can bypass many sperm abnormalities like reduced motility and severe morphological defects, an additional selection step based on the physiological ability of spermatozoa to bind to zona pellucida can be used to improve results after ICSI further.

This approach could also be applied in cases with poor semen characteristics. Sperm-zona binding test has been successfully applied in a group of patients with suboptimal semen characteristics (Franken et al. 1990). However, detailed information on the sperm-zona-adhesion properties in those men is missing. In teratozoospermic patients, the application of the combined swim-up and zona selection would help to isolate the spermatozoa with normal morphology. In cases such as asthenozoospermia, the yield of motile spermatozoa after swim-up would be very low. Further selection by zona-adhesion would result in much less spermatozoa compared to the samples used in this study. Thereby, the small percentage of sperm cells having high motility, membrane maturity, low SDF, and normal morphology would be easily distinguished from the whole sperm population. Therefore, future studies are needed to analyze the efficacy of the sperm zonaadhesion selection in patients with teratozoospermia and asthenozoospermia.
Therefore, in patients experiencing repeated IVF failures, an additional zona-selection step prior ICSI can be considered. In this way, we could avoid unpredicted IVF failure caused by one of the 'hidden' male factors associated with the membrane maturity of the sperm.

\section{Conclusion}

This study demonstrates that sperm selection by combined swim-up and zona-adhesion technique yields a significantly higher percentage of spermatozoa with normal morphology as well as a decreased level of DNA fragmentation when compared to the native semen and the swim-up-only prepared samples. The optimization of the sperm zona-selection technique would be beneficial if introduced in cases of 'hidden' male factor, in which normozoospermic men face reproductive failure due to underlying sperm DNA damage.

\section{Declaration of interest}

The authors declare that there is no conflict of interest that could be perceived as prejudicing the impartiality of the research reported.

\section{Funding}

This work did not receive any specific grant from any funding agency in the public, commercial, or not-for-profit sector.

\section{Human rights statement and informed consent}

All the procedures were followed in accordance with the ethical standards of the responsible committees on human experimentation (institutional and national) and in accordance with the Helsinki Declaration of 1964 and its later amendments. Informed consent was obtained from all the patients to be included in the study.

\section{Animal studies}

This article does not contain any study with animal participants that were performed by any of the authors.

\section{Author contribution statement}

R G, D P and G S contributed to study design. R G, N K, M V and D V contributed to data acquisition. R G and D P contributed to data analysis. All authors contributed to interpretation of data. R G and D P contributed to draft the paper or revised it critically. All authors have contributed to critical discussion and reviewed the final version of the article and approve it for publication.

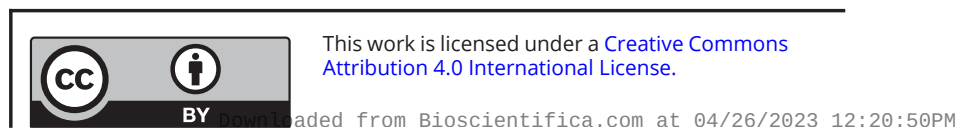




\section{Acknowledgement}

The authors are grateful to Yoanna Baleva-Zhelezarska for editing the manuscript and editorial assistance.

\section{References}

Arslan M, Morshedi M, Arslan EO, Taylor S, Kanik A, Duran HE \& Oehninger S 2006 Predictive value of the hemizona assay for pregnancy outcome in patients undergoing controlled ovarian hyperstimulation with intrauterine insemination. Fertility and Sterility 85 1697-1707. (https://doi.org/10.1016/j.fertnstert.2005.11.054)

Bartoov B, Berkovitz A, Eltes F, Kogosovsky A, Yagoda A, Lederman H, Artzi S, Gross M \& Barak Y 2003 Pregnancy rates are higher with intracytoplasmic morphologically selected sperm injection than with conventional intracytoplasmic injection. Fertility and Sterility 80 1413-1419. (https://doi.org/10.1016/j. fertnstert.2003.05.016)

Black M, Liu DY, Bourne H \& Baker HWG 2010 Comparison of outcomes of conventional intracytoplasmic sperm injection and intracytoplasmic sperm injection using sperm bound to the zona pellucida of immature oocytes. Fertility and Sterility 93 672-674. (https://doi.org/10.1016/j.fertnstert.2009.08.063)

Bourne H, Liu DY, Clarke GN \&Baker HW 1995 Normal fertilization and embryo development by intracytoplasmic sperm injection of round-headed acrosomeless sperm. Fertility and Sterility 63 1329-1332. (https://doi.org/10.1016/s0015-0282(16)57620-1)

Bradford MM 1976 A rapid and sensitive method for the quantitation of microgram quantities of protein utilizing the principle of protein-dye binding. Analytical Biochemistry 72 248-254. (https://doi.org/10.1006/ abio.1976.9999)

Braga D, Iaconelli Jr A, Cássia Sávio de Figueira R, Madaschi C, Semiao-Francisco L \& Borges Jr E 2009 Outcome of ICSI using zona pellucida-bound spermatozoa and conventionally selected spermatozoa. Reproductive Biomedicine Online 19 802-807. (https://doi. org/10.1016/j.rbmo.2009.09.020)

Burkman LJ, Coddington CC, Franken DR, Kruger TF, Rosenwaks Z \& Hodgen GD 1988 The hemizona assay (HZA): development of a diagnostic test for the binding of human spermatozoa to the human hemizona pellucida to predict fertilization potential. Fertility and Sterility 49 688-697. (https://doi.org/10.1016/ S0015-0282(16)59841-0)

Chen L, Fang J, Jiang W, Wang J \& Li D 2020 Effects of the sperm DNA fragmentation index on the clinical and neonatal outcomes of intracytoplasmic sperm injection cycles. Journal of Ovarian Research 13 52. (https://doi.org/10.1186/s13048-020-00658-z)

Chi HJ, Kim SG, Kim YY, Park JY, Yoo CS, Park IH, Sun HG, Kim JW, Lee KH \& Park HD 2017 ICSI significantly improved the pregnancy rate of patients with a high sperm DNA fragmentation index. Clinical and Experimental Reproductive Medicine 44 132-140. (https://doi.org/10.5653/cerm.2017.44.3.132)

Cissen M, Wely MV, Scholten I, Mansell S, Bruin JP, Mol BW, Braat D, Repping S \& Hamer G 2016 Measuring sperm DNA fragmentation and clinical outcomes of medically assisted reproduction: a systematic review and meta-analysis. PLOS ONE 11 e0165125. (https://doi.org/10.1371/journal.pone.0165125)

Dar S, Grover SA, Moskovtsev SI, Swanson S, Baratz A \& Librach CL 2013 In vitro fertilization-intracytoplasmic sperm injection outcome in patients with a markedly high DNA fragmentation index (>50\%). Fertility and Sterility 100 75-80. (https:// doi.org/10.1016/j.fertnstert.2013.03.011)

Evenson DP, Jost LK, Marshall D, Zinaman MJ, Clegg E, Purvis K, de Angelis P \& Claussen OP 1999 Utility of the sperm chromatin structure assay as a diagnostic and prognostic tool in the human fertility clinic. Human Reproduction 14 1039-1049. (https://doi. org/10.1093/humrep/14.4.1039)

Familiari G, Nottola SA, Micara G, Aragona C \& Motta PM 1988 Is the sperm binding capability of the zona pellucida linked to its surface structure? A scanning electron microscopic study of human in vitro fertilization. Journal of In Vitro Fertilization and Embryo Transfer $\mathbf{5}$ 134-143. (https://doi.org/10.1007/BF01131175)

Fernandez-Gonzalez R, Moreira PN, Perez-Crespo M, SanchezMartín M, Ramirez MA, Pericuesta E, Bilbao A, BermejoAlvarez P, Hourcade J, de Fonseca FR, et al. 2008 Long-term effects of mouse intracytoplasmic sperm injection with DNAfragmented sperm on health and behavior of adult offspring. Biology of Reproduction 78 761-772. (https://doi.org/10.1095/ biolreprod.107.065623)

Franken DR, Kruger TF, Menkveld R, Oehninger S, Coddington CC \& Hodgen GD 1990 Hemizona assay and teratozoospermia: increasing sperm insemination concentrations to enhance zona pellucida binding. Fertility and Sterility $\mathbf{5 4}$ 497-503. (https://doi.org/10.1016/s0015-0282(16)53769-8)

Franken DR, Coddington CC, Burkman LJ, Oosthuizen WT, Oehninger SC, Kruger TF \& Hodgen GD 1991 Defining the valid hemizona assay: accounting for binding variability within zonae Pellucidae and within semen samples from fertile males. Fertility and Sterility 56 1156-1161. (https://doi.org/10.1016/S0015-0282(16)54732-3)

Ganeva R, Parvanov D, Nikolova K, Gospodinova M, Ivanova I, Rangelov I, Vasileva M \& Stamenov G 2019a Predictive value of the sperm zona-adhesion score for the implantation outcome. EMJ Reproductive Health 5 46-47.

Ganeva R, Parvanov D, Vasileva M, Nikolova K \& Stamenov GS $2019 b$ Higher pregnancy rates after zona pellucida sperm selection. Fertility and Sterility 112 e280. (https://doi.org/10.1016/j. fertnstert.2019.07.826)

Ganeva R, Gospodinova M, Ivanova I, Rangelov I, Vasileva M, Nikolova K, Parvanov D, Chaushev T \& Stamenov G 2019c Method for utilization on solubilized zonae Pellucidae in sperm-zona adhesion test. Scientific Sessions of the Faculty of Biology 104 315-334.

Garolla A, Cosci I, Menegazzo M, De Pallo R, Ambrosini G, Sartini B, Pizzol D \& Foresta C 2014 Sperm selected by both birefringence and motile sperm organelle morphology examination have reduced deoxyribonucleic acid fragmentation. Fertility and Sterility 101 647-652. (https://doi.org/10.1016/j.fertnstert.2013.11.029)

Garrett C, Liu DY \& Baker HW 1997 Selectivity of the human sperm-zona pellucida binding process to sperm head morphometry. Fertility and Sterility 67 362-371. (https://doi.org/10.1016/S00150282(97)81924-3)

Gatimel N, Moreau J, Parinaud J \& Léandri RD 2017 Sperm morphology: assessment, pathophysiology, clinical relevance, and state of the art in 2017. Andrology 5 845-862. (https://doi.org/10.1111/ andr.12389)

Gil-Villa AM, Cardona-Maya W, Agarwal A, Sharma R \& Cadavid Á 2010 Assessment of sperm factors possibly involved in early recurrent pregnancy loss. Fertility and Sterility 94 1465-1472. (https://doi.org/10.1016/j.fertnstert.2009.05.042)

Hamada A, Esteves SC, Nizza M \& Agarwal A 2012 Unexplained male infertility: diagnosis and management. International Brazilian Journal of Urology 38 576-594. (https://doi.org/10.1590/s1677$55382012000500002)$

Huszar G, Ozenci CC, Cayli S, Zavaczki Z, Hansch E \& Vigue L 2003 Hyaluronic acid binding by human sperm indicates cellular maturity, viability, and unreacted acrosomal status. Fertility and Sterility 79 (Supplement 3) 1616-1624. (https://doi.org/10.1016/s00150282(03)00402-3)

Jakubik-Uljasz J, Gill K, Rosiak-Gill A \& Piasecka M 2020 Relationship between sperm morphology and sperm DNA dispersion. Translational Andrology and Urology 9 405-415. (https://doi. org/10.21037/tau.2020.01.31)

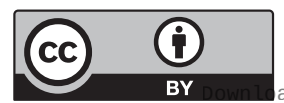

This work is licensed under a Creative Commons Attribution 4.0 International License. 
Jayaraman V, Upadhya D, Narayan PK \& Adiga SK 2012 Sperm processing by swim-up and density gradient is effective in elimination of sperm with DNA damage. Journal of Assisted Reproduction and Genetics 29 557-563. (https://doi.org/10.1007/s10815-012-9742-x)

Jin J, Pan C, Fei Q, Ni W, Yang X, Zhang L \& Huang X 2015 Effect of sperm DNA fragmentation on the clinical outcomes for in vitro fertilization and intracytoplasmic sperm injection in women with different ovarian reserves. Fertility and Sterility 103 910-916. (https:// doi.org/10.1016/j.fertnstert.2015.01.014)

Jin R, Bao J, Tang D, Liu F, Wang G, Zhao Y, Bai G, Liu Y, Wang Y, Liu L, et al. 2016 Outcomes of intracytoplasmic sperm injection using the zona pellucida-bound sperm or manually selected sperm. Journal of Assisted Reproduction and Genetics 33 597-601. (https://doi. org/10.1007/s10815-016-0676-6)

Kahraman S, Akarsu C, Cengiz G, Dirican K, Sözen E, Can B, Güven C \& Vanderzwalmen P 1999 Fertility of ejaculated and testicular megalohead spermatozoa with intracytoplasmic sperm injection. Human Reproduction 14 726-730. (https://doi.org/10.1093/ humrep/14.3.726)

Kizilay F \& Altay B 2017 Sperm function tests in clinical practice. Turkish Journal of Urology 43 393-400. (https://doi.org/10.5152/ tud.2017.96646)

Kodama H, Yamaguchi R, Fukuda J, Kasai H \& Tanaka T 1997 Increased oxidative deoxyribonucleic acid damage in the spermatozoa of infertile male patients. Fertility and Sterility 68 519-524. (https://doi. org/10.1016/s0015-0282(97)00236-7)

Kruger TF, Acosta AA, Simmons KF, Swanson RJ, Matta JF \& Oehninger S 1988 Predictive value of sperm morphology in in vitro fertilization. Fertility and Sterility 49 112-117. (https://doi.org/10.1016/ s0015-0282(16)59660-5)

Kumar D, Upadhya D, Uppangala S, Salian SR, Kalthur G \& Adiga SK 2013. Nuclear DNA fragmentation negatively affects zona binding competence of $Y$ bearing mouse spermatozoa. Journal of Assisted Reproduction and Genetics 30 1611-1615. (https://doi. org/10.1007/s10815-013-0123-x)

Li Z, Wang L, Cai J \& Huang H 2006 Correlation of sperm DNA damage with IVF and ICSI outcomes: a systematic review and meta-analysis. Journal of Assisted Reproduction and Genetics 23 367-376. (https://doi. org/10.1007/s10815-006-9066-9)

Lin YN, Roy A, Yan W, Burns KH \& Matzuk MM 2007 Loss of zona pellucida binding proteins in the acrosomal matrix disrupts acrosome biogenesis and sperm morphogenesis. Molecular and Cellular Biology 27 6794-6805. (https://doi.org/10.1128/MCB.01029-07)

Liu DY 2011 Could using the zona pellucida bound sperm for intracytoplasmic sperm injection (ICSI) enhance the outcome of ICSI? Asian Journal of Andrology 13 197-198. (https://doi.org/10.1038/ aja.2010.179)

Liu DY \& Baker HW 1992 Morphology of spermatozoa bound to the zona pellucida of human oocytes that failed to fertilize in vitro. Journal of Reproduction and Fertility 94 71-84. (https://doi.org/10.1530/ jrf.0.0940071)

Liu DY \& Baker HW 1994 Acrosome status and morphology of human spermatozoa bound to the zona pellucida and oolemma determined using oocytes that failed to fertilize in vitro. Human Reproduction 9 673-679. (https://doi.org/10.1093/oxfordjournals.humrep.a138570)

Liu DY \& Baker HW 2000 Defective sperm-zona pellucida interaction: a major cause of failure of fertilization in clinical in-vitro fertilization. Human Reproduction 15 702-708. (https://doi.org/10.1093/ humrep/15.3.702)

Liu DY \& Baker HW 2003 Frequency of defective sperm-zona pellucida interaction in severely teratozoospermic infertile men. Human Reproduction 18 802-807. (https://doi.org/10.1093/humrep/deg164)

Liu DY \& Baker HW 2007 Human sperm bound to the zona pellucida have normal nuclear chromatin as assessed by acridine orange fluorescence. Human Reproduction 22 1597-1602. (https://doi. org/10.1093/humrep/dem044)
Liu DY, Lopata A, Johnston WIH \& Baker HWG 1988 A human sperm \pm zona pellucida binding test using oocytes that failed to fertilize in vitro. Fertility and Sterility 50 782-788. (https://doi. org/10.1016/S0015-0282(16)60316-3)

Liu DY, Lopata A, Johnston WIH \& Baker HWG 1989 Human sperm: zona pellucida binding, sperm characteristics and in-vitro fertilization. Human Reproduction 4 696-701. (https://doi.org/10.1093/ oxfordjournals.humrep.a136969)

Liu F, Qiu Y, Zou Y, Deng ZH, Yang H \& Liu DY 2011 Use of zona pellucida-bound sperm for intracytoplasmic sperm injection produces higher embryo quality and implantation than conventional intracytoplasmic sperm injection. Fertility and Sterility 95 815-818. (https://doi.org/10.1016/j.fertnstert.2010.09.015)

Mackenna A 1995 Contribution of the male factor to unexplained infertility: a review. International Journal of Andrology 18 (Supplement 1) 58-61. (https://doi.org/10.1111/j.1365-2605.1995.tb00640.x)

Menkveld R, Franken DR, Kruger TF, Oehninger S \& Hodgen GD 1991 Sperm selection capacity of the human zona pellucida. Molecular Reproduction and Development 30 346-352. (https://doi.org/10.1002/ mrd.1080300409)

Menkveld R, Rhemrev JP, Franken DR, Vermeiden JP \& Kruger TF 1996 Acrosomal morphology as a novel criterion for male fertility diagnosis: relation with acrosin activity, morphology (strict criteria), and fertilization in vitro. Fertility and Sterility 65 637-644. (https://doi. org/10.1016/s0015-0282(16)58167-9)

Muratori M, Tarozzi N, Carpentiero F, Danti S, Perrone FM, Cambi M, Casini A, Azzari C, Boni L, Maggi M, et al. 2019 Sperm selection with density gradient centrifugation and swim up: effect on DNA fragmentation in viable spermatozoa. Scientific Reports 97492. (https://doi.org/10.1038/s41598-019-43981-2)

Oehninger S, Morshedi M \& Franken D 2013 The hemizona assay for assessment of sperm function. In Spermatogenesis. Methods in Molecular Biology (Methods and Protocols). Eds D Carrell \& K Aston. Humana Press.

Osawa Y, Sueoka K, Iwata S, Shinohara M, Kobayashi N, Kuji N \& Yoshimura Y 1999 Assessment of the dominant abnormal form is useful forpredicting the outcome of intracytoplasmic sperm injection in the case of severe teratozoospermia. Journal of Assisted Reproduction and Genetics 16 436-442. (https://doi. org/10.1023/A:1020573609836)

Osman A, Alsomait H, Seshadri S, El-Toukhy T\& Khalaf Y 2015 The effect of sperm DNA fragmentation on live birth rate after IVF or ICSI: a systematic review and meta-analysis. Reproductive Biomedicine Online 30 120-127. (https://doi.org/10.1016/j.rbmo.2014.10.018)

Parikh FR, Athalye AS \& Kulkarni DK 2019 Breaks and bends in sperm DNA: their impact on the future of the embryo. Fertility and Sterility 111 672-673. (https://doi.org/10.1016/j.fertnstert.2018.12.024)

Parmegiani L, Cognigni GE \& Filicori M 2014 Sperm selection: effect on sperm DNA quality. Advances in Experimental Medicine and Biology 791 151-172. (https://doi.org/10.1007/978-1-4614-7783-9 10)

Parrella A, Keating D, Cheung S, Xie P, Stewart JD, Rosenwaks Z \& Palermo GD 2019 A treatment approach for couples with disrupted sperm DNA integrity and recurrent ART failure. Journal of Assisted Reproduction and Genetics 36 2057-2066. (https://doi.org/10.1007/ s10815-019-01543-5)

Quinn MM, Jalalian L, Ribeiro S, Ona K, Demirci U, Cedars MI \& Rosen MP 2018 Microfluidic sorting selects sperm for clinical use with reduced DNA damage compared to density gradient centrifugation with swim-up in split semen samples. Human Reproduction 33 1388-1393. (https://doi.org/10.1093/humrep/dey239)

Ricci G, Perticarari S, Boscolo R, Montico M, Guaschino S \& Presani G 2009. Semen preparation methods and sperm apoptosis: swim-up versus gradient-density centrifugation technique. Fertility \& Sterility 91 632-638. (https://doi.org/10.1016/j.fertnstert.2007.11.068)

Robinson L, Gallos ID, Conner SJ, Rajkhowa M, Miller D, Lewis S, Kirkman-Brown J \& Coomarasamy A 2012 The effect of sperm

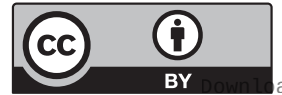

This work is licensed under a Creative Commons Attribution 4.0 International License. 
DNA fragmentation on miscarriage rates: a systematic review and meta-analysis. Human Reproduction 27 2908-2917. (https://doi. org/10.1093/humrep/des261)

Sadeghi MR 2015 Unexplained infertility, the controversial matter in management of infertile couples. Journal of Reproduction and Infertility $161-2$.

Saleh RA, Agarwal A, Nelson DR, Nada EA, El-Tonsy MH, Alvarez JG, Thomas AJ \& Sharma RK 2002 Increased sperm nuclear DNA damage in normozoospermic infertile men: a prospective study. Fertility and Sterility 78 313-318. (https://doi.org/10.1016/s00150282(02)03219-3)

Sharbatoghli M, Valojerdi MR, Amanlou M, Khosravi F \& Jafarabadi MA 2012 Relationship of sperm DNAfragmentation, apoptosis and dysfunction of mitochondrial membrane potential with semen parametersand ART outcome after intracytoplasmic sperm injection. Archives of Gynecology and Obstetrics 286 1315-1322. (https://doi. org/10.1007/s00404-012-2440-1)

Skowronek F, Casanova G, Alciaturi J, Capurro A, Cantu L, Montes JM \& Sapiro R 2012 DNA sperm damage correlates with nuclear ultrastructural sperm defects in teratozoospermic men. Andrologia 44 59-65. (https://doi.org/10.1111/j.14390272.2010.01106.X)

Stevanato J, Bertolla RP, Barradas V, Spaine DM, Cedenho AP \& Ortiz V 2008 Semen processing by density gradient centrifugation does not improve sperm apoptotic deoxyribonucleic acid fragmentation rates. Fertility and Sterility 90 889-890. (https://doi. org/10.1016/j.fertnstert.2007.01.059)

Szucs M, Osvath P, Laczko I \& Jakab A 2015 Adequacy of hyaluronan binding assay and a new fertility index derived from it for measuring of male fertility potential and the efficacy of supplement therapy. Andrologia 47 519-524. (https://doi.org/10.1111/and.12296)

Tan J, Taskin O, Albert A \& Bedaiwy MA 2019 Association between sperm DNA fragmentation and idiopathic recurrent pregnancy loss: a systematic review and meta-analysis. Reproductive Biomedicine Online 38 951-960. (https://doi.org/10.1016/j.rbmo.2018.12.029)

Von Bernhardi R, de Ioannes AE, Blanco LP, Herrera E, BustosObregon E \& Vigil P 1990 Round-headed spermatozoa: a model to study the role of the acrosome in early events of gamete interaction. Andrologia 22 12-20. (https://doi.org/10.1111/j.1439-0272.1990. tb01934.x)

Wang C \& Swerdloff RS 2014 Limitations of semen analysis as a test of male fertility and anticipated needs from newer tests.
Fertility and Sterility 102 1502-1507. (https://doi.org/10.1016/j. fertnstert.2014.10.021)

Wang M, Sun J, Wang L, Gao X, Lu X, Wu Z, Wang Y, Liu K, Tao J \& Wu Y 2014 Assessment of density gradient centrifugation (DGC) and sperm chromatin dispersion (SCD) measurements in couples with male factor infertility undergoing ICSI. Journal of Assisted Reproduction and Genetics 31 1655-1663. (https://doi.org/10.1007/s10815-014-0339-4)

World Health Organization 2010 WHO Laboratory Manual for the Examination and Processing of Human Semen, 5th ed. World Health Organization.

Yagci A, Murk W, Stronk J \& Huszar G 2010 Spermatozoa bound to solid state hyaluronic acid show chromatin structure with high DNA chain integrity: an acridine orange fluorescence study. Journal of Andrology 31 566-572. (https://doi.org/10.2164/jandrol.109.008912)

Yatsenko AN, O'Neil DS, Roy A, Arias-Mendoza PA, Chen R, Murthy LJ, Lamb DJ \& Matzuk MM 2012 Association of mutations in the zona pellucida binding protein 1 (ZPBP1) gene with abnormal sperm head morphology in infertile men. Molecular Human Reproduction 18 14-21. (https://doi.org/10.1093/molehr/gar057)

Zhang Z, Zhu L, Jiang H, Chen H, Chen Y \& Dai Y 2015 Sperm DNA fragmentation index and pregnancy outcome after IVF or ICSI: a metaanalysis. Journal of Assisted Reproduction and Genetics 32 17-26. (https:// doi.org/10.1007/s10815-014-0374-1)

Zhao J, Zhang Q, Wang Y \& Li Y 2014 Whether sperm deoxyribonucleic acid fragmentation has an effect on pregnancy and miscarriage after in vitro fertilization/intracytoplasmic sperm injection: a systematic review and meta-analysis. Fertility and Sterility 102 998.e8-1005.e8. (https://doi.org/10.1016/j.fertnstert.2014.06.033)

Zheng WW, Song G, Wang QL, Liu SW, Zhu XL, Deng SM, Zhong A, Tan YM \& Tan Y 2018 Sperm DNA damage has a negative effect on early embryonic development following in vitro fertilization. Asian Journal of Andrology 20 75-79. (https://doi.org/10.4103/aja.aja_19_17)

Zini A, Bielecki R, Phang D \& Zenzes MT 2001 Correlations between two markers of sperm DNA integrity, DNA denaturation and DNA fragmentation, in fertile and infertile men. Fertility and Sterility 75 674-677. (https://doi.org/10.1016/s0015-0282(00)01796-9)

Received in final form 6 July 2021

Accepted 12 August 2021

Accepted Manuscript published online 16 August 2021 (c) 2021 The authors Published by Bioscientifica Ltd

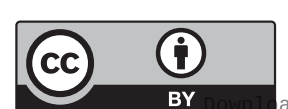

This work is licensed under a Creative Commons Attribution 4.0 International License. 